\title{
Mathematics support centre attendees and their use of online resources
}

Ciarán Mac an Bhaird, Department of Mathematics and Statistics, Maynooth University, Ireland.

Email: ciaran.macanbhaird@mu.ie

Peter Mulligan, Department of Mathematics and Statistics, Maynooth University, Ireland.

Email: peter.mulligan@mu.ie

James O'Malley, Department of Mathematics and Statistics, Maynooth University, Ireland.

Email: james.omalley@mu.ie

\begin{abstract}
In this paper we consider survey results which focus on student use of online resources, where all respondents were attendees of a Mathematics Support Centre. We see that while most respondents are engaging with online resources, some are not using resources in an appropriate fashion. We discuss how these preliminary findings might inform discussions on the merits, or otherwise, of institutions providing training for students on their use of online materials. We also identify several areas of potential further research.
\end{abstract}

Keywords: Online resources, mathematics support, usage, reliability.

\section{Introduction}

In Mac an Bhaird et al. (2020), we present an evaluation of the Mathematics Support Centre (MSC) website (http://supportcentre.maths.nuim.ie/) at Maynooth University (MU). The evaluation is based on findings from a survey issued to MU undergraduates in 2018. Prior to the development of the survey, a literature review identified that, to the best of our knowledge, no research on MSC websites had been undertaken. Thus, in order to give the website evaluation some local context, we decided to place additional questions at the start of our survey on student use of online supports in general. The responses to these questions are the main focus of this paper. To provide some broader international context to our website evaluation, we also sent a survey on the online presence of MSCs across Ireland and the UK to institutional co-ordinators of Mathematics Learning Support (MLS), and we will report on those findings elsewhere (Mac an Bhaird et al., in preparation).

In this paper, we provide a brief overview of the rationale for and methodology of our study. These are presented in more detail in Mac an Bhaird et al. (2020). The main focus of this paper is on the results, and a discussion on how this small study may link to literature and further research regarding why certain groups of students use online resources in particular ways. We close with some consideration of how our findings, albeit from a small sample, highlight a need for institutions to promote and advertise both online resources and appropriate student engagement with these resources.

\section{Background}

The MSC was established in MU in 2007 and, from the very beginning, a visible online presence was identified as playing a key role in student awareness of and engagement with the MSC, especially in terms of advertisement of services (Lawson et al., 2003). Initially our website was a basic webpage with operational information such as location, opening hours etc. It went through several iterations and now has a series of webpages featuring operational information and links to a large number of mostly external online resources. The online resources are organised according to subject area, e.g. Differential and Integral Calculus, Ordinary Differential Equations, Introduction to 
Statistics etc. These subject areas are the normal source of queries with which 1 st and 2 nd year students attend the MSC drop-in.

The MSC normally provides 27 hours of drop-in each week to MU undergraduates. It is based in the Department of Mathematics and Statistics (the Department), and the majority of MSC attendees are students taught by the Department, i.e. degree and pre-degree (Certificate) undergraduates. The majority of students in our Department take 'service mathematics' courses, for example mathematics as part of a Science, Arts or Finance degree. Also, for all first year Science and Certificate students, mathematics is compulsory. Generally, students attend the MSC to work on their assignments, the results of which contribute to their continuous assessment grade. Students in the Department receive at least one assignment each week, and tutors at the MSC assist students if or when they get stuck but will not do the assignment for them.

Furthermore, the MSC also provides weekly workshops for the main first year classes, and workshop notes are placed on dedicated Moodle pages along with links to related online resources. Moodle is MU's Virtual Learning Environment. Until 2019 there were also 'on-demand' workshops for other year groups, and the notes were hosted on the MSC website for one week.

In early 2018 we were made aware that the MSC might lose control of the layout and content of the MSC website. In order to challenge this potential change, we decided to try to evaluate the impact of our website. As outlined previously, a review of MLS literature identified no research in this area. Indeed, a recent paper, which gives a literature review of the evolution of MLS, identifies no research in this area (Lawson et al., 2019). Thus, we decided that it was important to conduct this research project, to inform our and potentially other practices in the provision of MSC websites and MLS online presences.

\section{Methodology}

In early 2018, we developed and tested a survey which was hosted on google forms. The survey had two parts. The first section, which is reported on in this paper, mainly focussed on students' use of online resources. The second part related to the MSC website and is reported on separately (Mac an Bhaird et al., 2020).

Ethical approval was sought and granted for the survey and during April 2018, the survey was placed on Moodle. Via the Moodle messaging facility, all students registered with the Department had access to the survey and were invited to participate. The survey was also advertised in the MSC. In total, 99 undergraduates completed the survey, with responses from all academic years and all respondents were MSC users. The results of the survey were coded and analysed using the software package SPSS.

Responses to all questions reported on in this paper were crosschecked with other survey questions and issues of importance to the research questions were noted.

\section{Results}

All respondents were asked 'Do you use online resources to assist with your MU coursework?', 59 indicated that they did and 40 that they did not.

\subsection{Students Who Use Online Resources ( $n=59)$}

The 59 respondents were asked to select how often they used online resources to assist with their MU coursework, with fixed options 'At least once a day' (10), 'At least once a week' (25), 'At least once a month' (16), and 'At least once a semester' (8). 
Respondents were then asked to indicate which option best described how they used online resources. They were given five fixed options, and an option to give an open response which no one did. Students could select more than one answer. Forty selected 'I use online resources to help understand material from my lectures', 38 that 'I use online resources to help me understand how to approach a homework problem', and 30 that 'I use online resources to help study for exams'. Fourteen respondents selected either 'I use online resources to find exact worked solutions to a homework problem' (10) or 'I use online resources to replace any lecture material that I've missed' (6). Of these 14 respondents, 13 also selected at least one of the other fixed options, and nine were Certificate or First Year students.

We asked respondents, in an open question, to briefly describe how they find the online resources that they use. There were 79 responses, of which 76 contained relevant information. Coded responses fell into the following categories: $29 \mathrm{MU}$ or MSC specific guidance such as 'MSC Workshops' (11), 'Staff Recommendations' (9), 'Other Student Recommendations' (6) and 'Moodle' (3); 32 'Search Engine' use, e.g. Google (21), and 'YouTube' (11); other responses highlighted specific websites such as 'Khan Academy' (10) and 'Paul's Online Notes' (2); and three mentioned 'Online Calculator'.

Respondents were then asked, in an open question, if they used a search engine to source online resources, to briefly describe how they choose which of the resources to use. There were 34 responses, mostly from 'Search Engine' respondents to the last question but also including some from respondents who had selected 'Moodle', 'Staff Recommendations' or 'MSC Workshops'. Coding of responses gave two broad categories. Fourteen referred to using familiar websites or resources they have used in the past 'I tend to look at YouTube views or websites/users I have seen before.' with three of these (in response to a later question) stating that they always considered the reliability of online resources.

Twenty referred to new searches, in other words random or arbitrary searches and not previously used resources or specific websites. Fifteen of these 20 reported some level of consideration about the suitability of what they found 'Whether the title of the link closely resembles what I'm looking for'. Six of these 15 always thought about the reliability of online resources. The remaining five (of 20) gave little or no justification 'Just pick the first link that comes up', though three of these indicated that they always thought about the reliability of online resources.

Respondents were asked to select what type of resources they found most helpful and, in an open response, to briefly explain why they found this type of resource helpful. The majority (30) selected 'either video or text, depends what I find', 20 selected 'Videos', and 9 selected 'Text'. No respondents selected the 'Other' option. Of these 59 respondents, 48 provided the explanation requested. Fortytwo of these had selected 'Videos' or 'either video or text...' while 6 had selected 'Text', and responses were spread across the following five categories of codes. Twenty-six liked the step by step nature and high-level of detail provided in online examples 'Goes through examples explaining every step'. Nine made reference to the ability to go at a pace that they are comfortable with 'It's like being at a lecture that I can pause at any moment and replay'. Four preferred to use resources that appeal to their learning style 'I'm a visual learner'. Two referenced the engaging nature of videos for their choice of resource 'If you find someone that has a good personality and enthusiasm then video is much more enjoyable than reading pages of size 11 black text on an a4 piece of paper'. The final 6 gave very general responses, such as 'everything helps' or 'both are equally helpful'.

Finally, in this section of the survey, we asked respondents if they thought about the reliability of online resources before they used them. They were given fixed options 'Always' (23), 'Sometimes' (33) and 'Never' (3). When we considered the various year groups, responses from undergraduates were spread across each of the fixed options, though for each year group the majority of respondents did not pick 'Always'. All four Certificate students who answered this question selected 'Always'. 


\subsection{Students Who Do Not Use Online Resources ( $n=40$ )}

These 40 respondents were evenly spread across the various year groups and 37 of them reported that they attended the MSC at least once a day or at least once a week. They were asked why they did not use online resources, and of the responses given, 38 were relevant. Seventeen stated a lack of awareness of online supports. Eleven referred to a preference for physical one-to-one support 'I find that I can understand more easily from the tutors' explanations'. Nine of these 11 respondents were 3rd year or higher and they also selected elsewhere that they attended the MSC at least once a day. Three, two final years and one 1st year, cited a lack of suitable online material for their course 'Most of the time they don't seem fully relevant to my course material....... which is different to the online resources available'. Three other respondents, two 3rd year and one 2nd year, said that they did not need online resources. Two felt that online resources are unreliable 'Don't trust the content majority of the time...', while the final two suggested that online resources do not help them 'Sometimes they don't help me understand it enough'.

The 40 respondents were also asked what would encourage them to start using online resources and 39 gave relevant responses. Seventeen referred to advertising and providing information about the available resources 'If people mentioned them and said that they were useful. Sometimes I wouldn't even think to look'. Eleven said they would use online resources is they were tailored to match the content of their lectures and assignments 'If they were personally adapted to our modules and courses'. Seven of these 11 respondents were 3rd year or higher. Three respondents suggested availability issues, and two said they would use online resources if they could not access the MSC 'If the maths support centre was no longer available for help'. There were also 5 other miscellaneous responses such as 'more time', 'I will now research the online resources' and 'Unsure exactly what I could personally further require'.

\section{Discussion, conclusion and future work}

The survey reported on in this paper and in Mac an Bhaird et al. (2020) is of narrow scope, and there are several papers which look at student use of (online) resources in a broader (non-MSC specific) context, for example Ní Shé et al. (2017) and Van de Sande et al. (2014). However, the responses to our survey do suggest preliminary discussion points on MSC attendees' use of online resources, which may be of use to those considering the expansion of their provision of online mathematical resources or, indeed, to any researchers who want to investigate this subject area in further detail.

Some of the data seems to paint a positive picture. In our Department, students have at least one graded assignment each week, and the majority (59) of the 99 respondents indicated that they were using online resources to assist with their coursework, and 35 of these reported using online resources at least once a day or once a week. Respondent approaches to finding online materials, for example via search engines, do not appear unusual when compared to those reported in other studies (Conole et al., 2006, Ní Shé et al., 2017).

When asked why they were using online resources, the majority of respondents selected options which mentioned understanding lecture material, understanding how to approach assignment questions or when studying for exams. This appears encouraging, for example Anastasakis et al. (2017), who considered links between student goals and their choice of educational resource, also reported high incidences of students expressing a desire to improve their understanding and to prepare for exams.

There is also some evidence that respondents' use of online resources '.... (and perceptions of 'what works' best) are clearly being shaped by the university contexts within which students are situated as much as they are being driven by individual 'choice' and agency,...' (Henderson et al., 2015, p.1577). Twenty-nine of 76 responses mentioned MU guidance when referring to how they find the 
resources that they used. Furthermore, the reasons given by respondents for the helpfulness of the resource types that they used were very positive and are similar to those reported elsewhere (Henderson et al., 2015, Ní Shé et al., 2017).

Bray and Tangney (2017, p.265), state ' ... although use of technology in the classroom is increasing, its implementation in the mathematics classroom, and indeed in related research, still lags behind its perceived potential to enhance the learning experience'. As we carefully consider what future role we may take in the provision of online resources for students, there are several causes for concern arising from this study that require, at a minimum, further investigation.

Fourteen respondents indicated that they were not always using online resources appropriately, i.e. they used them to replace missed lecture material or looked up exact solutions to assignment problems. Nine of these respondents were 1st year or Certificate students, for whom mathematics is compulsory. This is worrying and suggests several avenues for research which lie outside the scope of this survey data. For example, are there links with existing research, such as that of Baynard reported in Hilton (2002), who noted that some engineering students viewed their first year mathematics course as an obstacle to overcome in order to study the topics they are interested in. Furthermore, while we did not ask for respondents' mathematical background, in a previous study (Berry et al., 2009) at MU we found that 1st year students who were at-risk of failing or dropping out were more likely to attend the MSC and stay for longer than their peers who were not at-risk. There is a danger, as reported in Chi et al. (1989), that 'poor' students are not capable of extracting the information they need from worked solutions to apply it to their problems. Institutions can play a key role in addressing these concerns. Also, as reported in Mac an Bhaird et al. (in preparation), there are other potential downsides for students who chose online resources instead of face-to-face support, as suggested by the following comment from an institutional co-ordinator of MLS:

"Some students may see ICT support as a sufficient alternative to visiting the MSSC and speaking to a tutor face-to-face. Without doing so, they may not correctly self-diagnose whatever issues they are facing and this may lead them to concentrating on material that won't help them overcome these issues."

Thirty-two respondents mentioned the use of search engines when finding resources, of these 20 used 'new searches' and only nine of these always considered the reliability of the resources that they used. Indeed, overall, just 23 of 59 respondents always considered the reliability of the resources that they used. Again, the institution has the opportunity to play an important role, as reported in our survey of MLS practitioners (Mac an Bhaird et al., in preparation) and highlighted by the following comment:

"I suspect that students just use google to search for materials rather than looking at the collated sets of materials collected on a site. I think where it can be helpful to have collections of resources is for lecturers who can link to these from their VLE module pages to ensure consistency and quality of additional resources provided to students that way. I think students will go to specific resources on a particular topic that are linked from the VLE page." [Institutional Co-ordinator of MLS].

If we consider those who reported that they did not use online resources, the most common reason given was lack of awareness, something that could be resolved within the institution, for example, via the lecturer or via an MSC if they provide links to online resources. Once the advertisement issue is resolved however, there is no guarantee that students will avail themselves of online resources. Respondents, mainly those towards the end of their degree, indicated a preference for 1-1 support. A similar point was raised by institutional co-ordinators of MLS in Mac an Bhaird et al. (in preparation), for example: 
"...it's just that our students value our face-to-face provision so much they find that much more useful, engaging, and suitable [than online supports]."

When asked what would encourage them to use online resources, again the majority referred to appropriate advertisement. The second most common response was if the resources were more tailored to respondents' courses, with the majority of these comments coming from higher year students. These findings are consistent with what we found in Mac an Bhaird et al. (2020), when respondents were asked what would encourage them to use the MSC website and MSC resources.

We believe that our limited findings bolster one of the recommendations from Mac an Bhaird et al. (2020), that institutions should consider the provision of training to students on appropriate use of online resources as part of their education. There appears to be a need, amongst our student population at least, to be guided on how to source and evaluate online resources, as well as how to use them in conjunction with more traditional forms for learning. There also needs to better and continuous advertisement of the online resources that are available to students.

\section{References}

Anastasakis, M., Robinson, C. and Lerman, S., 2017. Links between students' goals and their choice of educational resources in undergraduate mathematics. Teaching Mathematics and its Applications, 36(2), pp.67-80, https://doi.org/10.1093/teamat/hrx003

Berry, E., Mac an Bhaird, C. and O'Shea, A., 2009. Investigating relationships between the usage of Mathematics Learning Support and performance of at-risk students. Teaching Mathematics and its Applications, 34(4), pp.194-204, https://doi.org/10.1093/teamat/hrv005

Bray, A. and Tangney, B., 2017. Technology usage in mathematics education research - A systematic review of recent trends. Computers \& Education, 114, pp.255-273, https://doi.org/10.1016/j.compedu.2017.07.004

Chi, M., Bassok, M., Lewis, M., Reimann, P. and Glaser, R., 1989. Self-explanations: how students study and use examples in learning to solve problems. Cogn. Sci., 13, pp.145-182, https://psycnet.apa.org/doi/10.1207/s15516709cog1302 1

Conole, G., De Laat, M., Dillon, T. and Darby, J., 2006. JISC LXP Student experiences of technologies. JISC Report. Available via http://citeseerx.ist.psu.edu/viewdoc/download?doi $=10.1 .1 .454 .1292 \& \mathrm{rep}=$ rep1\&type $=$ pdf [Accessed 10 January 2020].

Henderson, M., Selwyn, N. and Aston, R., 2017. What works and why? Student perceptions of 'useful' digital technology in university teaching and learning. Studies in Higher Education, 42(8), pp.1567-1579, https://doi.org/10.1080/03075079.2015.1007946

Hilton, M.L., National Research Council (U.S.). Center for Education, Division of Behavioral and Social Sciences and Education, Center for Education, National Research Council \& Board on Science Education 2002, Enhancing undergraduate learning with information technology: a workshop summary, National Academy Press, Washington, DC.

Mac an Bhaird, C., Mulligan, P. and O'Malley, J., 2020. Student Perspectives on their Engagement with a Mathematics Support Centre Website. MSOR Connections, 18(3), pp.4-9.

Mac an Bhaird, C., Mulligan, P. and O'Malley, J. (in preparation). Mathematics Support Centres' Online Presence: Provision in Ireland and the UK in 2018. 
Ní Shé, C., Mac an Bhaird, C., Ní Fhloinn, E. and O'Shea, A., 2017. Students' and lecturers' views on mathematics resources. Teaching Mathematics and its Applications, 36(4), pp.183-199, https://doi.org/10.1093/teamat/hrw026

Van De Sande, C., Boggess, M. and Hart-weber, C., 2014. How do high school students get help on their mathematics homework? A study of digital and non-digital resource use. J. Comput. Math. Sci. Teach., 33, pp.455-483. 